\title{
Smad3 signaling is required for satellite cell function and myogenic differentiation of myoblasts
}

Xiaojia Ge ${ }^{1}$, Craig McFarlane ${ }^{2}$, Anuradha Vajjala ${ }^{1}$, Sudarsanareddy Lokireddy ${ }^{1}$, Zhi Hui $\mathrm{Ng}^{1}$, Chek Kun Tan ${ }^{1}$, Nguan Soon Tan ${ }^{1}$, Walter Wahli ${ }^{3}$, Mridula Sharma ${ }^{4}$, Ravi Kambadur ${ }^{1,2}$

${ }^{I}$ School of Biological Sciences, Nanyang Technological University, 60 Nanyang Drive, Singapore; ${ }^{2}$ Singapore Institute for Clinical Sciences, Agency for Science, Technology and Research (A*STAR), Brenner Centre for Molecular Medicine, 30 Medical Drive, Singapore 117609; ${ }^{3}$ Center for Integrative Genomics, NCCR Frontiers in Genetics, University of Lausanne, Lausanne, Switzerland; ${ }^{4}$ Department of Biochemistry, Yong Loo Lin School of Medicine, National University of Singapore, Singapore

TGF- $\beta$ and myostatin are the two most important regulators of muscle growth. Both growth factors have been shown to signal through a Smad3-dependent pathway. However to date, the role of Smad3 in muscle growth and differentiation is not investigated. Here, we demonstrate that Smad3-null mice have decreased muscle mass and pronounced skeletal muscle atrophy. Consistent with this, we also find increased protein ubiquitination and elevated levels of the ubiquitin E3 ligase MuRF1 in muscle tissue isolated from Smad3-null mice. Loss of Smad3 also led to defective satellite cell (SC) functionality. Smad3-null SCs showed reduced propensity for self-renewal, which may lead to a progressive loss of SC number. Indeed, decreased SC number was observed in skeletal muscle from Smad3null mice showing signs of severe muscle wasting. Further in vitro analysis of primary myoblast cultures identified that Smad3-null myoblasts exhibit impaired proliferation, differentiation and fusion, resulting in the formation of atrophied myotubes. A search for the molecular mechanism revealed that loss of Smad3 results in increased myostatin expression in Smad3-null muscle and myoblasts. Given that myostatin is a negative regulator, we hypothesize that increased myostatin levels are responsible for the atrophic phenotype in Smad3-null mice. Consistent with this theory, inactivation of myostatin in Smad3-null mice rescues the muscle atrophy phenotype.

Keywords: Smad3; myostatin; muscle atrophy; satellite cells

Cell Research (2011) 21:1591-1604. doi:10.1038/cr.2011.72; published online 19 April 2011

\section{Introduction}

The ability of skeletal muscle to regenerate is due to availability of adult muscle stem cells, termed satellite cells (SCs) [1]. SCs are quiescent cells that are located between the basal lamina and sarcolemma. Upon injury to skeletal muscle, SCs are activated to enter the cell cycle and as a result rapidly proliferate to give rise to myoblasts, which then differentiate and fuse to give rise to multinucleated nascent muscle fibers [2]. At the same time, some of the myoblasts re-enter the quiescent phase to self-renew the SC population. Among several growth

Correspondence: Ravi Kambadur

Tel: +65-6513-8043

E-mail: KRavi@ntu.edu.sg

Received 8 November 2010; revised 14 January 2011; accepted 15 February 2011; published online 19 April 2011 factors, myostatin (GDF8) has been shown to be a profound regulator of the skeletal muscle during prenatal and postnatal growth. Disruption of the myostatin gene or inhibition of myostatin expression in mice leads to increased skeletal muscle growth, which is due to both muscle hyperplasia (increase in muscle fiber number) and hypertrophy (increase in muscle fiber size) $[3,4]$. In contrast, overexpression of myostatin in mice results in reduced skeletal muscle mass, and decreased muscle fiber size and myonuclear number [5]. Moreover, systemic overexpression of myostatin in adult mice leads to the development of cachectic-like muscle wasting [6]. Myostatin functions by inhibiting myoblast proliferation and differentiation [7], as well as negatively regulating SC activation and SC self-renewal $[8,9]$. In addition to myostatin, TGF- $\beta$ has also been shown to inhibit myogenesis $[10,11]$. Mechanistically, the $\operatorname{Smad} 2 / 3$ pathway plays a significant role in myostatin and TGF- $\beta$ signaling and 
inhibition of myogenesis $[10,11]$. Specifically, Smad3 is required for the inhibition of myoblast differentiation by myostatin [12] and for the activation of fibroblast proliferation by myostatin [13]. The Smad3-dependent pathway begins when activated myostatin receptors (activin type IIB receptor/ALK5) form heterotetrameric complexes, which then recruit, phosphorylate and activate the receptor-regulated SMADS (R-Smads). The newly activated Smad3 complexes with Smad4 and then translocates to the nucleus to activate/repress the expression of genes regulating muscle growth and differentiation. Although Smad3 is a key signaling molecule/transcription factor, its role in SC biology is not studied in greater detail. Here, we make use of Smad3-null mice and show that Smad3 is essential for normal skeletal muscle growth, as the absence of Smad3 promotes dramatic skeletal muscle atrophy accompanied with defective SC functionality, impaired in vitro myogenesis and enhanced skeletal muscle protein degradation. Interestingly, loss of Smad3 results in the up-regulation of myostatin expression. Furthermore, the elevated level of myostatin plays a key role in the development of the skeletal muscle atrophy observed in Smad3-null mice.

\section{Results}

Smad3-null mice demonstrate pronounced skeletal muscle atrophy

Smad3-null mice had an overall reduction in body size; however, there was no significant decrease in the muscle weights when calculated as a percentage of body weight (Supplementary information, Figure S1A-S1C and Table S1). To evaluate muscle fiber histology, $M$. tibialis anterior (TA) muscles were sectioned and stained with hematoxylin and eosin (H \& E; Supplementary information, Figure S1D). As shown in Supplementary information, Figure S1E, no significant difference in muscle fiber number was noted between wild-type (WT) and Smad3-null mice. However, Smad3-null mice had a greatly reduced muscle fiber cross-sectional area (CSA) when compared to WT mice (Figure 1A). Specifically, in WT mice, $\sim 63 \%$ of muscle fibers had an area of $\geq 2000$ $\mu \mathrm{m}^{2}$; however, in the Smad3-null mice, only $\sim 8 \%$ were found to be of similar diameter.

\section{Smad3-null primary myoblasts have a reduced rate of proliferation}

One of the reasons for postnatal muscular atrophy is the impaired myogenic nature of SCs. In order to analyze myogenic potential, proliferation rate of myoblasts derived from Smad3-null SCs and WT SCs were compared in vitro. Data showed that Smad3-null primary myoblasts had a significantly reduced proliferation rate when compared to WT primary myoblasts (Figure 1B). In addition, we generated a Smad3-knockdown C2C12 cell line (shSmad3; Supplementary information, Figure S2), and analysis of proliferation demonstrated that short hairpin RNA (shRNA)-mediated knockdown of Smad3 also results in a reduction in the proliferation rate (Figure $1 \mathrm{C})$. Consistent with the reduced proliferation, fluorescence-activated cell sorting (FACS) revealed that shRNAmediated knockdown of $S m a d 3$ results in a reduction in the percentage of cells in $\mathrm{S}$ phase of the cell cycle, concomitant with increased percentages of cells in both $G_{1}$ and $G_{2} / M$ phases of the cell cycle (Table 1). Cyclin-dependent kinase $2(\mathrm{Cdk} 2)$, cyclin-E and retinoblastoma $(\mathrm{Rb})$ protein have all been shown to be critical in regulating the $\mathrm{G}_{1} / \mathrm{S}$ transition in myoblasts [19]. Therefore, we next analyzed the levels of these proteins via western blot analysis. As shown in Figure 1D, down-regulation or inactivation of Smad3 leads to reduced expression of both Cdk2 and cyclin-E (Figure 1D). Rb is the major substrate of G1 Cdks; moreover, Cdk-mediated phosphorylation of $\mathrm{Rb}$ relieves its repression on E2F/DP1, resulting in continued cell cycle progression [7]. Subsequent western blot analysis revealed a reduction in the levels of hyperphosphorylated $\mathrm{Rb}\left(\mathrm{pRb}^{\mathrm{PP}}\right)$ in both Smad3-null primary myoblasts and shSmad3 $\mathrm{C} 2 \mathrm{C} 12$ cells, concomitant with an increase in hypophosphorylated $\mathrm{Rb}$ ( $\mathrm{pRb}$; Figure 1D).

\section{Smad3-null primary myoblasts show impaired myogenic differentiation}

In addition to the proliferation rate, we also measured the differentiation ability of Smad3-null myoblasts. The results demonstrate that Smad3-null myoblasts differentiated to form smaller myotubes with reduced branching, as compared to WT myoblasts (Supplementary information, Figure S3). Consistent with the histology, gene expression results showed that the critical myogenic genes, Myf5, p21, MyoD, myogenin and MyHC, are downregulated in Smad3-null myotubes, especially in early $(0$ h) and late phases of differentiation ( $72 \mathrm{~h}$ and $96 \mathrm{~h}$ ) when compared to WT cultures (Figure 1E and Supplementary

Table 1 Cell cycle distribution of shSmad3 C2C12 myoblasts and control

\begin{tabular}{llll}
\hline Genotype & Cells in $\mathrm{G}_{1}$ & Cells in $\mathrm{S}$ & Cells in $\mathrm{G}_{2} / \mathrm{M}$ \\
\hline shSmad3 $(\%)$ & $70.32 \pm 0.58$ & $18.54 \pm 0.20$ & $11.14 \pm 0.38$ \\
Control (\%) & $67.00 \pm 0.79$ & $22.15 \pm 0.71$ & $10.87 \pm 0.08$ \\
\hline
\end{tabular}

Percentages of cells from 10000 counts in $\mathrm{G}_{1}, \mathrm{~S}$ or $\mathrm{G}_{2} / \mathrm{M}$ phases of the cell cycle were analyzed by FACS. Data are given as mean \pm SEM $(n$ $=2$ ). Statistical differences were determined by two-tailed Student's $t$-test. $P_{\mathrm{S}}<0.01$ and $P_{\mathrm{G} 1}<0.05$. 
A

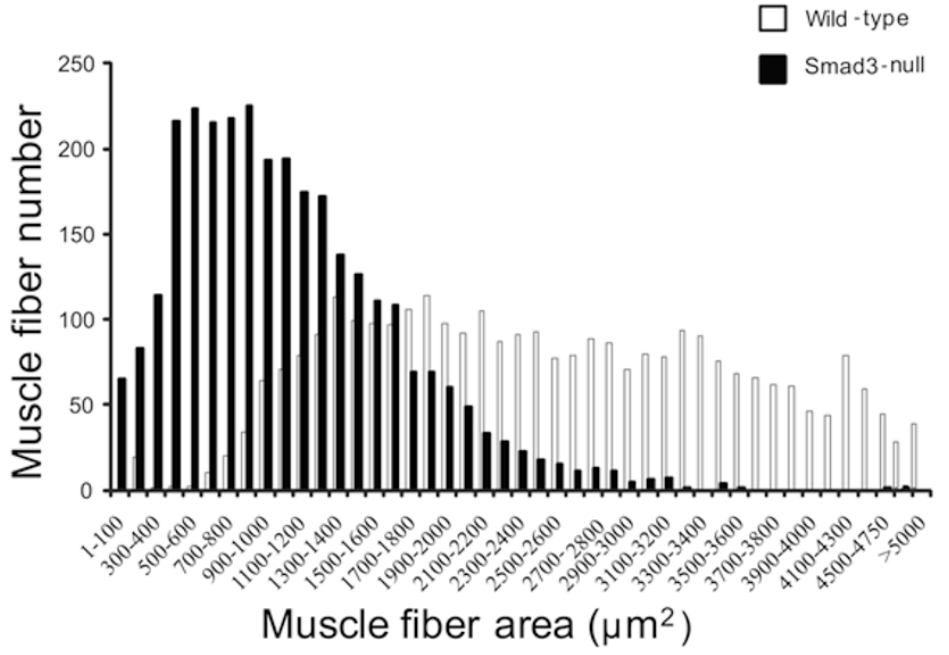

D
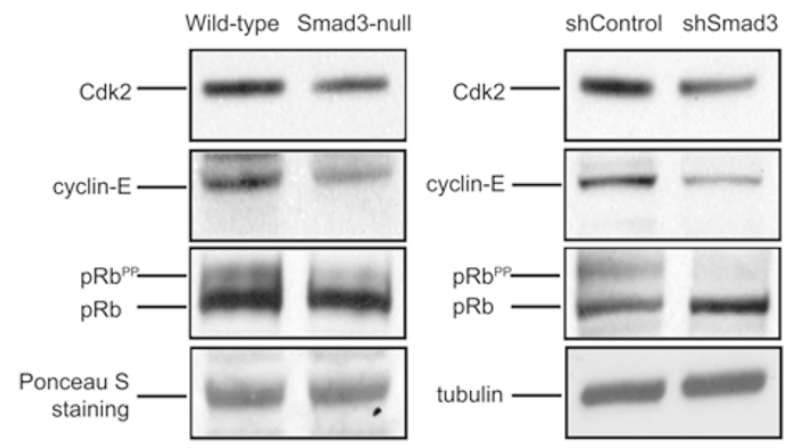

E

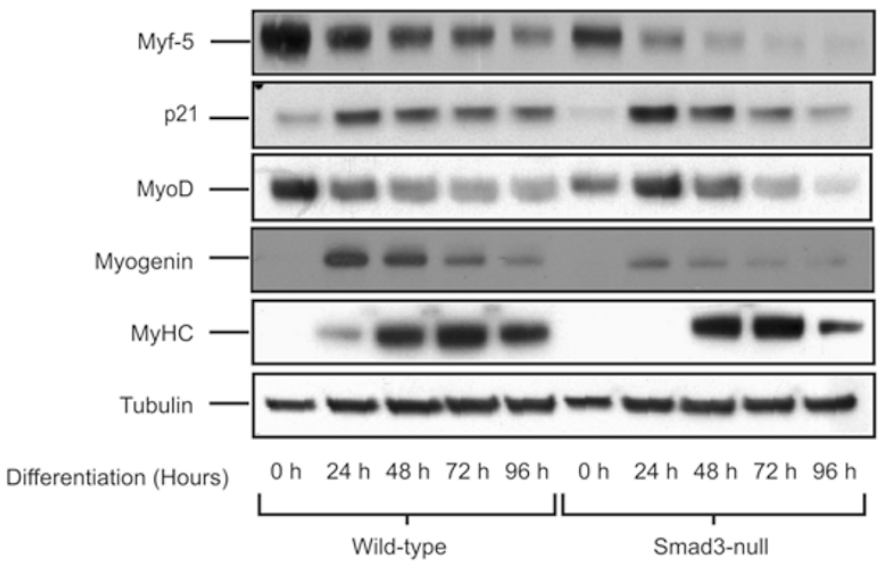

$\mathrm{H}$

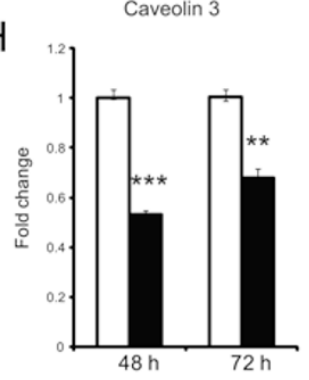

$\beta, D$ integrin

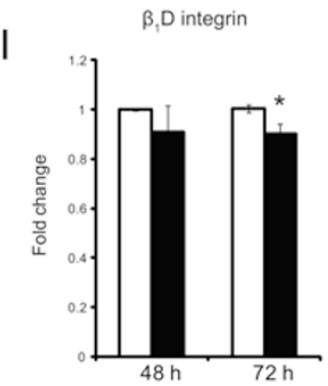

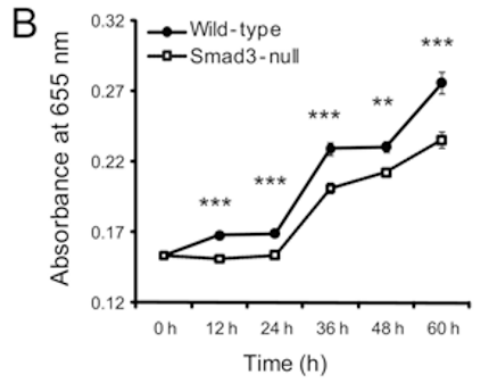

C

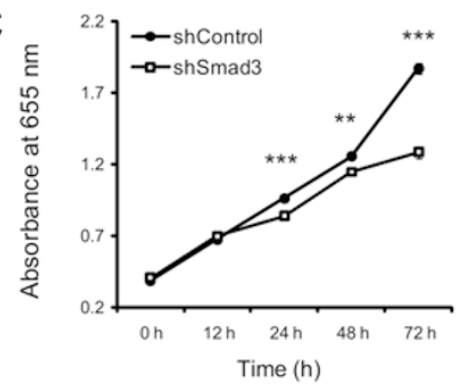

Wild - type

Smad3-null

F

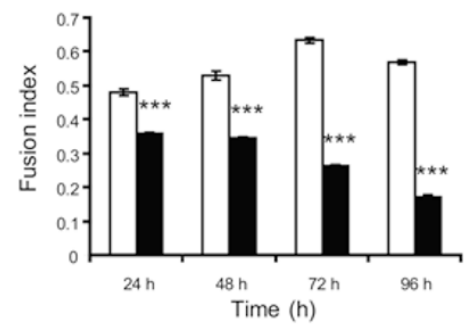

G

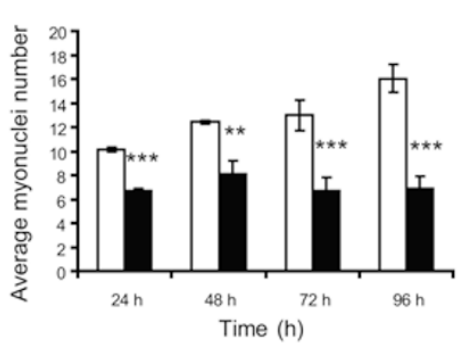

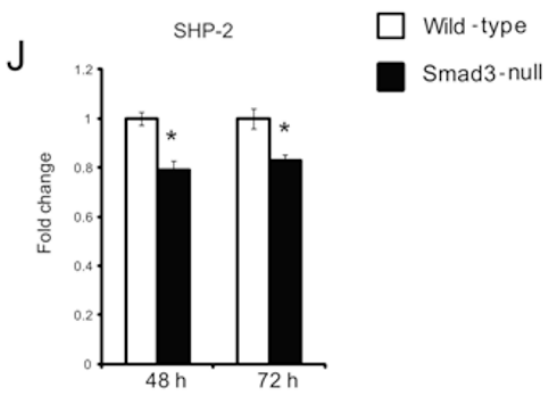


information, Figure S4).

This defective differentiation can also result from inefficient fusion of myoblasts and myotubes. Therefore, we determined fusion index of Smad3-null myotubes. Our analysis showed that the Smad3-null myotubes had decreased fusion index and reduced average myonuclei number (Figure 1F and 1G). This suggests that Smad3null myoblasts and myotubes have fusion defects during differentiation. We also analyzed the expression levels of some of the genes that have been shown to be involved in fusion during myogenesis. Caveolin-3 is a scaffolding protein primarily associated with caveolae membrane domains in skeletal muscle tissue [20]. $\beta_{1} D$ integrin is a muscle-specific membrane receptor, which appears to play a critical role in myoblast fusion [21, 22]. SHP-2 (SH2 domain-containing protein tyrosine phosphatase) positively regulates myogenesis through activation of RhoA [23], and the resulting phosphorylation of focal adhesion kinase (FAK) is essential for myoblast fusion [24]. Results from real-time PCR analysis showed that these fusion-related genes were down-regulated in Smad3-null myotubes at late time points ( $48 \mathrm{~h}$ and $72 \mathrm{~h}$ ) (Figure $1 \mathrm{H}-$ $1 \mathrm{~J})$, further supporting the fusion defects observed in the Smad3-null myoblasts.

\section{The role of Smad3 signaling in regulation of SC function}

As described earlier, Smad3-null mice show signs of muscular atrophy, which we hypothesized, that may be attributed to impaired SC function, namely SC self-renewal. We used two independent experimental systems, namely, tissue-dissociated SC and single muscle fiber culture to quantify SC self-renewal. The self-renewal ability of Smad3-null myoblasts was quantified through in vitro immunostaining analysis using antibodies directed against MyoD and Pax7 (Figure 2A). Cells that are positive for MyoD only $\left(\mathrm{MyoD}^{+} / \mathrm{Pax} 7\right)$ were considered fusion competent and cells positive for Pax7 only $\left(\mathrm{MyoD} / \mathrm{Pax} 7^{+}\right.$) were quantified as a measure of the fu- sion incompetent, self-renewing lineage (quiescent $\mathrm{SCs}$ ). The results indicate that there was a significant decrease in the percentage of $\mathrm{MyoD} / \mathrm{Pax} 7^{+}$myoblasts (from 19 $\% \pm 0.95 \%$ to $9 \% \pm 0.63 \%$ ), with a concomitant increase in the percentage of the $\mathrm{MyoD}^{+} / \mathrm{Pax}^{-}$myoblast population (from $27 \pm 0.84 \%$ to $40 \pm 2.87 \%$ ) in Smad3null myoblasts when compared to WT (Figure 2B) in the tissue-dissociated SC experimental system. Similarly in single muscle fiber cultures, we observed a significant reduction in the self-renewed population of SCs (Figure $2 \mathrm{C}$ and 2D). We next quantified SC numbers through immunostaining with Pax 7 antibodies (Supplementary information, Figure S5). Our results show that Smad3null mice had significantly reduced SC number when compared to WT controls (Figure 2E and 2F). Therefore, $\mathrm{Smad} 3$ appears to play a role in the regulation of SC function. Specifically, loss of $\mathrm{Smad} 3$ results in reduced SC self-renewal capacity, which may lead to a progressive decrease in the number of SCs.

\section{Altered levels of myostatin and IGF-1 are observed in Smad3- null skeletal muscle tissue and primary myoblast cultures}

In order to analyze the molecular basis for the observed atrophy, we performed real-time PCR analysis to measure the expression of candidate genes that regulate muscular atrophy, such as myostatin and IGF-1. The expression of myostatin was up-regulated in Smad3-null $M$. quadriceps (Quad) muscle (Figure 3A). In contrast, the expression of IGF-1 was significantly down-regulated in Quad muscles from Smad3-null mice when compared to WT controls (Figure 3B). In addition, we analyzed the expression of both myostatin and IGF-1 in primary myoblast cultures isolated from both Smad3-null and WT mice. Consistent with the results outlined above, we find increased expression of myostatin concomitant with reduced expression of IGF-1 in Smad3-null primary myotube cultures when compared to WT mice-derived cultures (Figure 3C and 3D).

Figure 1 Characterization of skeletal muscle atrophy in Smad3-null mice. (A) Frequency distribution of $M$. tibialis anterior (TA) skeletal muscle fiber CSA between WT and Smad3-null mice. (B, C) Smad3-null primary myoblasts and shSmad3 C2C12 cells were grown under proliferating conditions for a period of $60 \mathrm{~h}$ and $72 \mathrm{~h}$, respectively, with proliferation monitored using the methylene blue assay. Error bars represent \pm SEM $(n=2)$. (D) Western blot analysis of Cdk2, cyclin-E and Rb in primary myoblasts (left) and shSmad3 C2C12 cells (right). Ponceau S staining and analysis of tubulin expression were performed to ensure equal loading of samples. The hyperphosphorylated $\left(\mathrm{pRb}^{\mathrm{PP}}\right)$ and hypophosphorylated $(\mathrm{pRb})$ forms of Rb are indicated. (E) Western blot analysis of Myf5, p21, MyoD, myogenin, MyHC and tubulin expression at $0 \mathrm{~h}, 24 \mathrm{~h}, 48 \mathrm{~h}, 72 \mathrm{~h}$ and $96 \mathrm{~h}$ of differentiation in WT and Smad3-null primary myotubes. Tubulin expression was analyzed to ensure equal loading of samples. (F) Fusion index of WT and Smad3-null myoblasts at 24 h, 48 h, 72 h and 96 h of differentiation. Error bars represent \pm SEM $(n=3)$. (G) Total average myonuclei number in WT and Smad3-null myotubes at $24 \mathrm{~h}, 48 \mathrm{~h}, 72 \mathrm{~h}$ and $96 \mathrm{~h}$ of differentiation. Error bars represent \pm SEM $(n=3)$. (H-J) Relative mRNA expression levels of caveolin $3, \beta_{1} D$ integrin and SHP2 in WT and Smad3-null primary myotubes as measured by quantitative real-time PCR. Graphs display fold change \pm SEM, normalized to Gapdh $(n=3)$. For all relevant figure panels, statistical differences are indicated, $P<0.05\left(^{*}\right), P<0.01\left(^{* *}\right)$ and $\left.P<0.001{ }^{* * *}\right)$. 


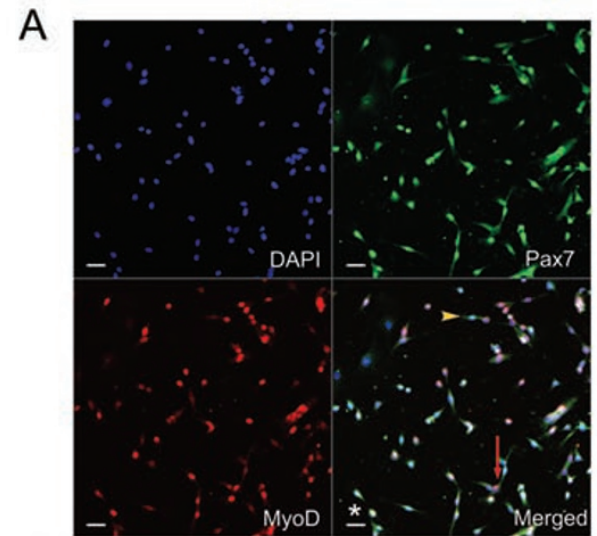

B

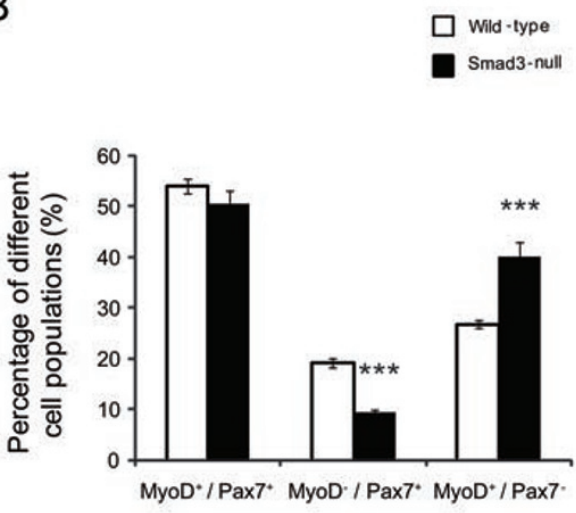

C

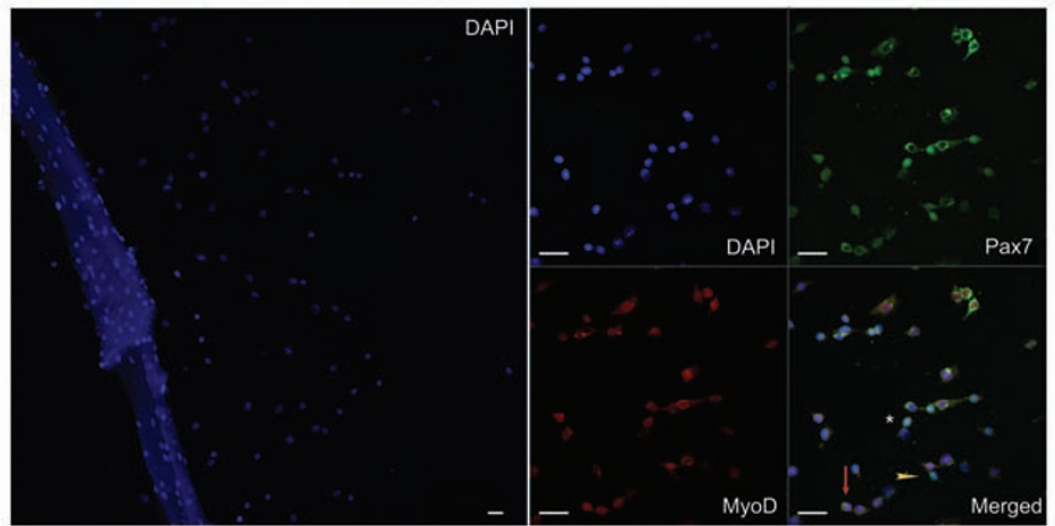

D

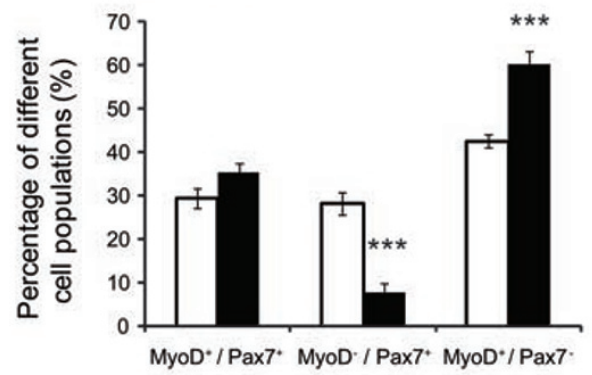

E

$\mathrm{F}$
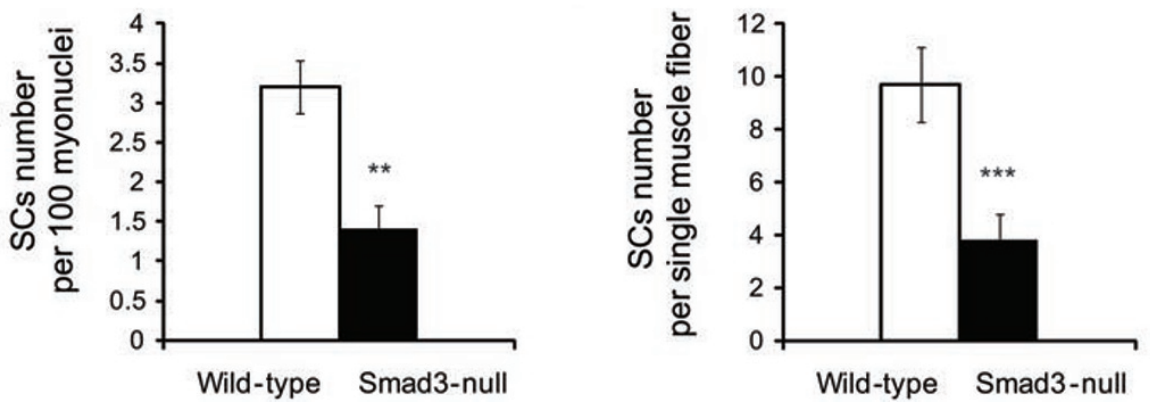

Figure 2 Satellite cell (SC) number and self-renewal in Smad3-null mice. Representative images of MyoD and Pax7 immunostaining on tissue-dissociated SCs (A) or SCs migrated from single muscle fibers (C). MyoD ${ }^{-} / \mathrm{Pax}^{+}$(yellow arrowheads), $\mathrm{MyoD}^{+} / \mathrm{Pax}^{-}$(red arrows) and $\mathrm{MyoD}^{+} / \mathrm{Pax}^{+}$(white asterisks) populations are indicated. Scale bar represents $50 \mu \mathrm{m}$. The graph represents the proportions of $\mathrm{MyoD}^{+} / \mathrm{Pax}^{+}, \mathrm{MyoD}^{-} / \mathrm{Pax} 7^{+}$and $\mathrm{MyoD} / \mathrm{Pax} 7^{-}$cells expressed as a percentage of total cell number in tissue-dissociated SCs (B) or in single muscle fiber cultures (D). (E) The graph represents the number of SCs, per 100 myonuclei (\%), in single muscle fibers isolated from Smad3-null and WT mice. (F) The graph represents the number of SCs per single muscle fiber. Error bars represent $\pm \operatorname{SEM}(n=3)$. For all relevant figure panels, statistical differences are indicated, $\left.P<0.01{ }^{* *}\right)$ and $P<0.001\left(^{* * *}\right)$. 
Increased ubiquitination of proteins in Smad3-null skeletal muscle

Since Smad3-null mice have increased levels of myostatin and decreased levels of IGF-1, we next investigated if there was an increase in ubiquitination of intracellular proteins in Smad3-null muscles. Indeed proteins of Quad muscle in the molecular weight range of 22-60 $\mathrm{kDa}$ appear to be highly ubiquitinated as compared to WT muscles (Figure 4A), which is consistent with the increased muscle atrophy observed. However, despite the increase in myostatin, there was no change in the expression and phosphorylation status of FoxO1 (Figure 4A). In addition, both mRNA expression and protein level of MuRF1 were up-regulated, while no change in the expression of Atrogin1 was observed, in the muscle tissue from Smad3-null mice when compared to controls (Figure 4A and 4B). MuRF1 has been previously demonstrated to interact with and promote the degradation of $\mathrm{MyHC}$ protein in myotubes treated with dexamethasone (DEX) [25]. Consistent with this, we find decreased expression of MyHC at the protein level in Smad3-null mice, with no appreciable change in mRNA expression of MyHC detected between WT and Smad3-null muscle tissue (Figure 4A and 4B). Muscle mass is maintained through a balance of protein synthesis and protein degradation. Therefore, we next analyzed the expression of Akt, a key signaling intermediate involved in protein synthesis. Western blot analysis demonstrated that the expression and
A

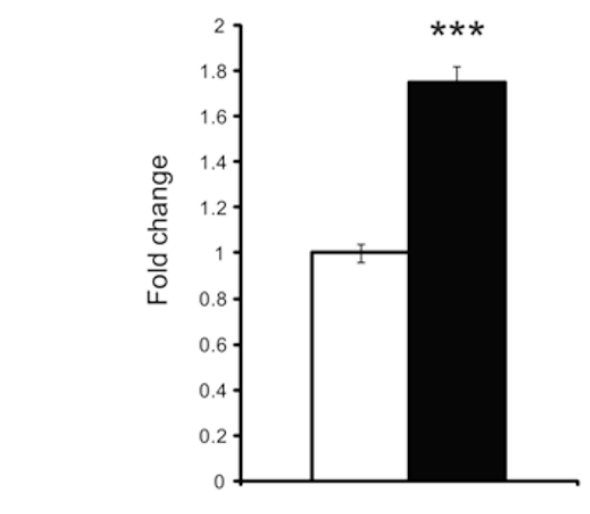

C

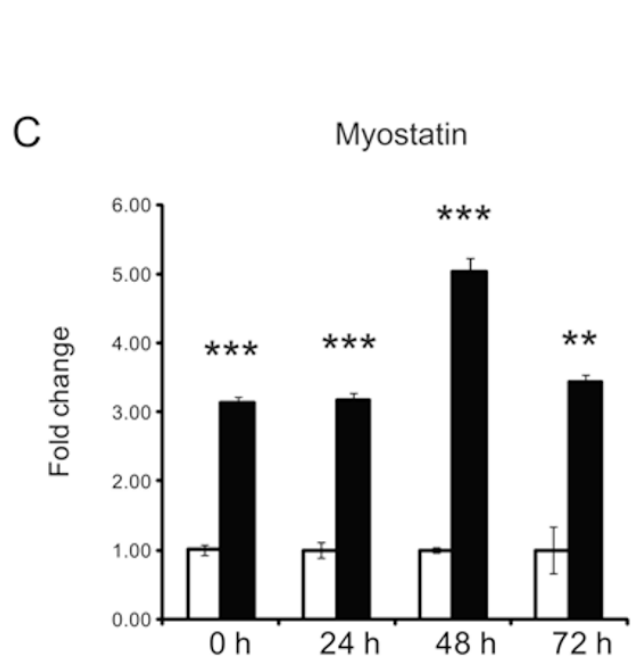

Myostatin
B

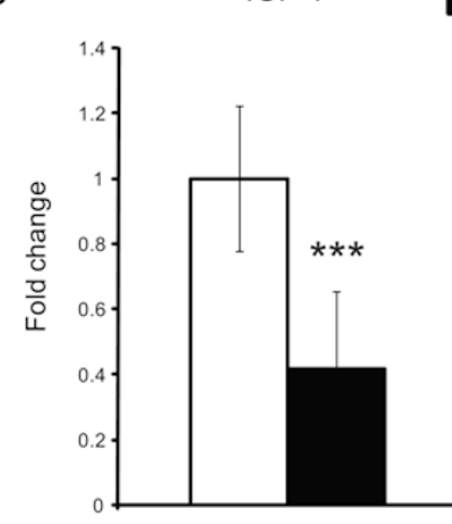

Wild - type

Smad3-null

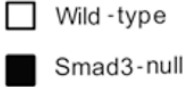

IGF-1

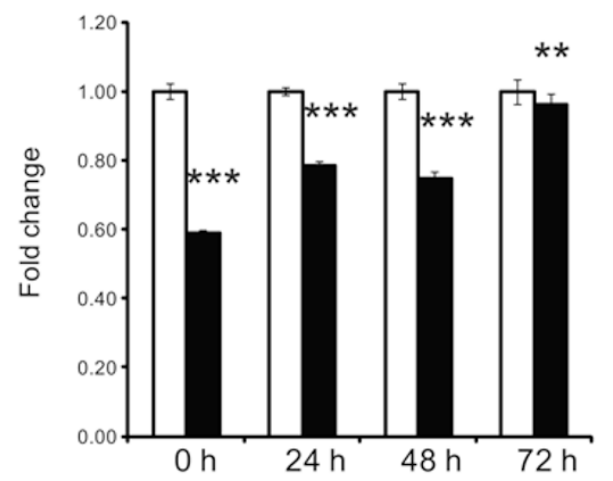

Figure 3 Myostatin and IGF-1 expression in Smad3-null muscle and primary myotubes. Relative mRNA expression levels of myostatin (A) and Igf-1 (B), as measured by quantitative real-time PCR in quad muscle tissue from WT and Smad3-null mice. Relative mRNA expression levels of myostatin (C) and Igf-1 (D), as measured by quantitative real-time PCR in primary myotube cultures from WT and Smad3-null mice. Graphs display fold change \pm SEM, normalized to Gapdh $(n=3)$. For all figure panels, statistical differences are indicated, $\left.P<0.01{ }^{* *}\right)$ and $P<0.001\left(^{* * *}\right)$. 
A

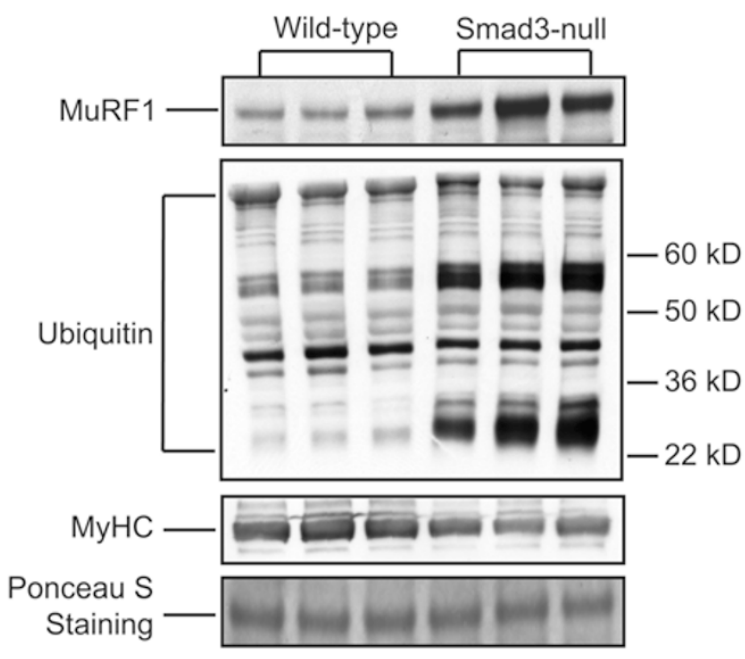

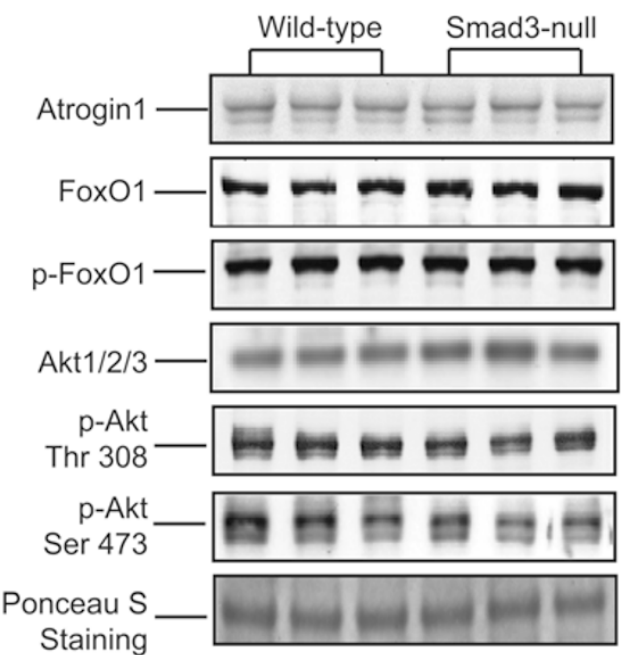

B
MyHC IIB

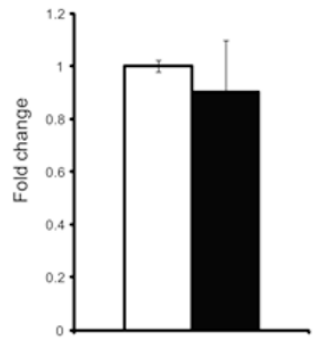

$\square$ Wild-type

Smad3-null
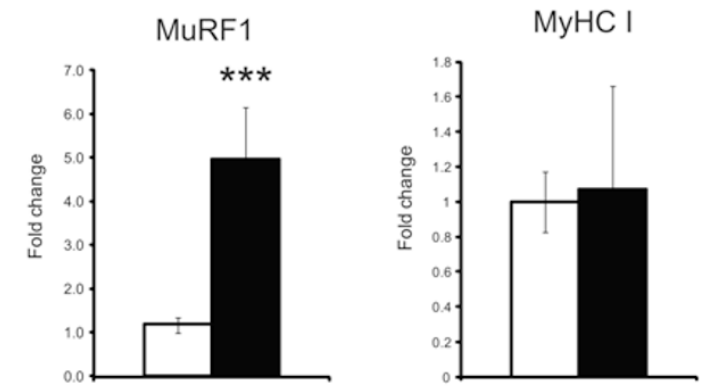

C

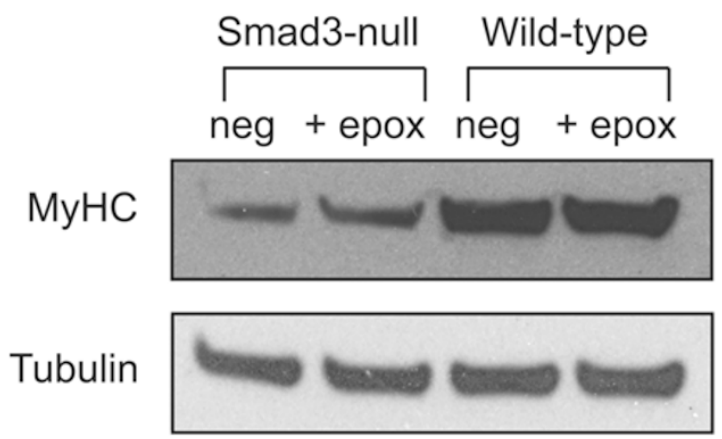

D

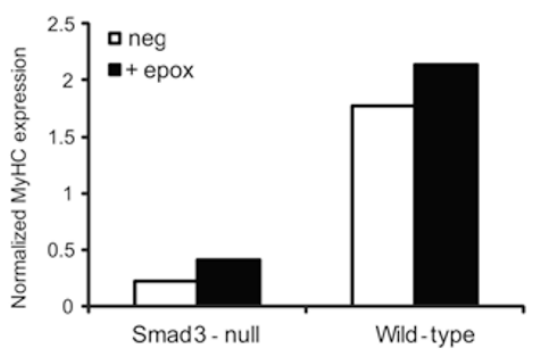

Figure 4 Ubiquitination of intracellular proteins in Smad3-null skeletal muscle. (A) Western blot analysis of MuRF1, ubiquitin, MyHC, Atrogin1, FoxO1, p-FoxO1, Akt, p-Akt (Thr308) and p-Akt (Ser473) expression in quad muscle from WT and Smad3null mice. Ponceau S staining was performed to ensure equal loading of samples. (B) Quantitative real-time PCR analysis of MuRF1, MyHC I, MyHC IIB and MyHC IIX expression in muscle of WT and Smad3-null mice. Graphs display fold change \pm SEM, normalized to Gapdh $(n=3)$. (C) Treatment of proteasome inhibitor epoxomicin in WT and Smad3-null primary myotubes. Differentiated WT and Smad3-null primary myotubes $(48 \mathrm{~h})$ were incubated with epoxomicin (48 $\mathrm{h}+100 \mathrm{nM}$ epox) or without epoxomicin ( $48 \mathrm{~h}+0 \mathrm{nM}$ epox) for $10 \mathrm{~h}$ before sample collection. The MyHC expression was measured by western blot analysis. Tubulin levels were measured to ensure equal loading of samples. (D) The expression of MyHC in WT and Smad3-null primary myotubes treated with or without epoxomicin, normalized to tubulin expression. For all the relevant figure panels, statistical differences are indicated, $P<0.001\left(^{* * *}\right)$. 
the level of active phosphorylated Akt remained unaltered between Smad3-null and WT muscle tissue (Figure 4A).

Treatment with proteasome inhibitor reduces $M y H C$ degradation in Smad3-null primary myotubes

Smad3-null skeletal muscle demonstrated elevated protein ubiquitination and MuRF1 expression level, which suggested the involvement of the ubiquitin-proteasome system in Smad3-null muscle atrophy. A proteasome inhibitor, epoxomicin (epox), was used to determine whether inhibition of the ubiquitin-proteasome system will ameliorate the loss of MyHC protein in Smad3null myotubes. Smad3-null primary myotubes showed significantly reduced MyHC expression as compared to WT primary myotubes. However, $10 \mathrm{~h}$ treatment with epox partially improved the MyHC expression in Smad3-null myotubes (Figure 4C and 4D). This partial rescue of MyHC expression in Smad3-null myotubes with the treatment of epox suggested that the proteasome system might be involved in myotube atrophy in Smad3-null mice.

Inactivation of myostatin partially alleviates the muscle atrophy and impaired myogenesis observed in Smad3null mice

In order to genetically prove that increased myostatin is responsible for the observed muscular atrophy in Smad3-null mice, we crossed the Smad3-null mice into a myostatin-null genetic background to generate a doubleknockout mouse model (DKO; Smad3 ${ }^{-/} /$myostatin $^{-/}$). Inactivation of mature myostatin expression and expression of an inactive Smad3 allele are shown in Supplementary information, Figure S7.
DKO mice have reduced body size and decreased musculature when compared to myostatin-null mice (Supplementary information, Figure S6A). Skeletal muscle weights were similar between DKO mice and WT mice; however, when muscle weights were normalized to total body weight, we found increased skeletal muscle mass when compared to that of WT mice (Supplementary information, Table S1 and Figure 5A, 5B). Histological analysis of muscle sections (Supplementary information, Figure S6B) indicated that muscle CSA of DKO was similar to that of WT (Figure 5C). However, quantification of muscle fiber number revealed an increase in fiber number in muscle sections from DKO mice when compared to WT controls, which suggests that the increased muscle mass observed in the DKO mice may be due to muscle fiber hyperplasia (Figure 5D), consistent with the phenotype observed in myostatin-null mice. Despite increased muscle fiber number, DKO mice had decreased average muscle fiber area when compared to WT controls, which is similar to that observed in the Smad3-null mice (Figure 5E). Therefore, inactivation of myostatin in Smad3-null mice rescues, at least in part, the atrophic phenotype observed in the Smad3-null mice, resulting in an increase in muscle mass back to levels comparable to WT mice. Furthermore, it appears that the improvement in muscle mass results from an increase in muscle fiber number (hyperplasia), rather than an increase in individual muscle fiber area (hypertrophy).

We next isolated primary myoblasts from DKO mice and analyzed their myogenic potential in vitro. DKO myoblasts had a significantly increased proliferation rate when compared to WT myoblasts (Figure 5F). Analysis

Figure 5 Reduced atrophy in double-knockout (DKO) mice $\left(\mathrm{Smad3}^{-1-}, \mathrm{Mstn}^{-1-}\right)$. (A) Quantification of the change in individual skeletal muscle weights between DKO and WT mice. TA denotes $M$. tibialis anterior. Gas and sol denotes $M$. gastrocnemius and soleus. Quad denotes M. quadriceps. Error bars represent $\pm \operatorname{SEM}(n=3)$. (B) Individual muscle weights from DKO and WT mice expressed as a percentage of total body weight. Error bars represent \pm SEM $(n=3)$. (C) Comparison of the average TA muscle CSA $\left(\mu \mathrm{m}^{2}\right)$ between Smad3-null, WT, DKO and myostatin-null mice. Difference between Smad3-null and DKO mice is not significant $(P>0.05)$. Error bars represent \pm SEM $(n=3)$. (D) Quantification of the total muscle fiber number in TA muscles from Smad3-null, WT, DKO and myostatin-null mice. Error bars represent \pm SEM $(n=3)$. (E) Frequency distribution of individual muscle fiber CSA in TA muscles from Smad3-null, WT and DKO mice, expressed as a percentage of total fiber number. Muscle fiber areas were grouped based on size: $<1000 \mu \mathrm{m}^{2}, 1000-2500 \mu \mathrm{m}^{2}$ and $>2500 \mu \mathrm{m}^{2}$. (F) WT, myostatinnull and DKO primary myoblasts were grown under proliferating conditions for a period of $60 \mathrm{~h}$, with proliferation monitored using the methylene blue assay. Error bars represent \pm SEM $(n=2)$. (G) The fusion index of WT, Smad3-null, myostatin-null and DKO myoblasts at $24 \mathrm{~h}, 48 \mathrm{~h}, 72 \mathrm{~h}$ and $96 \mathrm{~h}$ of differentiation. Error bars represent \pm SEM $(n=3)$. (H) Average myonuclei number in WT, Smad3-null, myostatin-null and DKO myotubes at 24 h, 48 h, $72 \mathrm{~h}$ and $96 \mathrm{~h}$ of differentiation. Error bars represent \pm SEM $(n=3)$. (I) Neutralization of myostatin in WT and Smad3-null primary culture by soluble ActRIIB treatment. WT and Smad3-null primary myoblasts were seeded at a density of 25000 cells $/ \mathrm{cm}^{2}$. Following a $12 \mathrm{~h}$ attachment period, cells were switched to differentiation media with $(0 \mathrm{~h}+3 \mu \mathrm{g} / \mathrm{ml}$ soluble ActRIIB) or without soluble ActRIIB $(0 \mathrm{~h}+0 \mu \mathrm{g} / \mathrm{ml}$ soluble ActRIIB) for $48 \mathrm{~h}$. The MyHC and MyLC expression were measured by western blot analysis. Tubulin levels were measured to ensure equal loading of samples. $(\mathrm{J})$ The expression of MyHC and MyLC in WT and Smad3-null primary culture treated with or without soluble ActRIIB, normalized to tubulin expression. For all relevant figure panels, statistical differences are indicated, $P<0.05\left(^{*}\right), P<0.01\left(^{* *}\right)$ and $P<0.001\left(^{* * *}\right)$. 
A

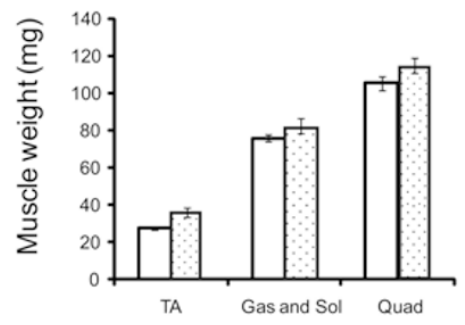

C

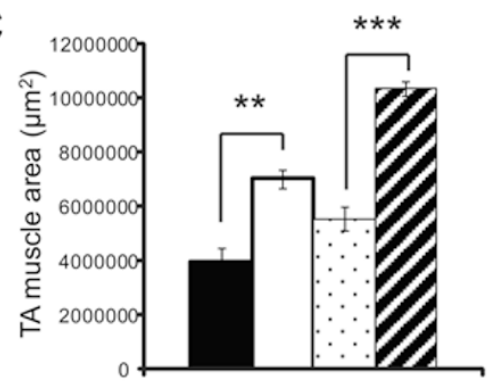

E

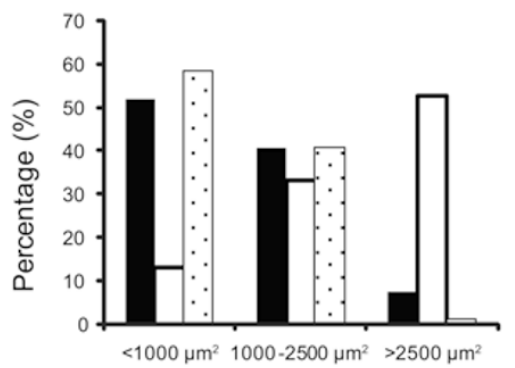

G

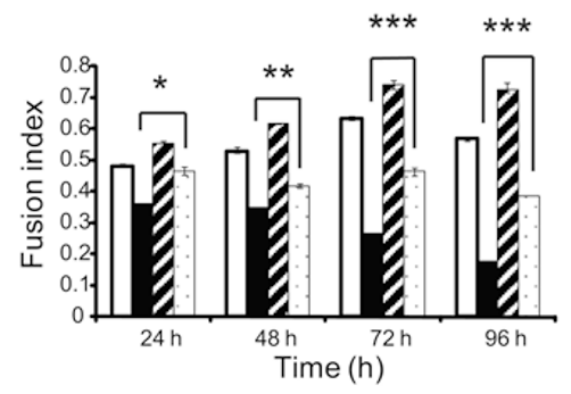

B

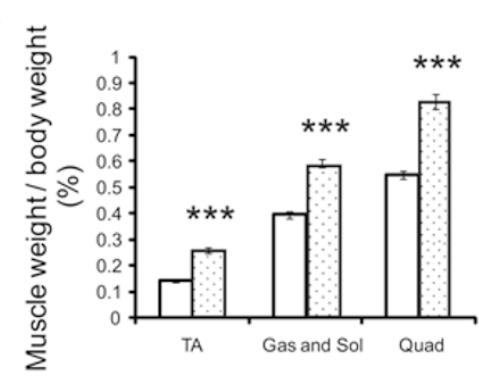

D

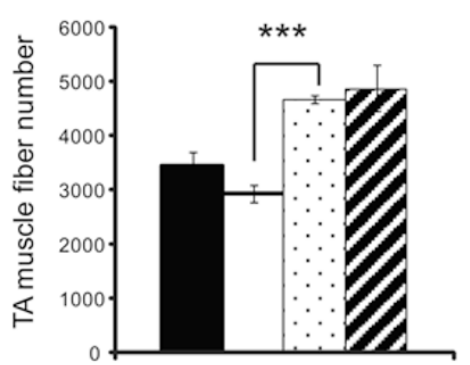

F

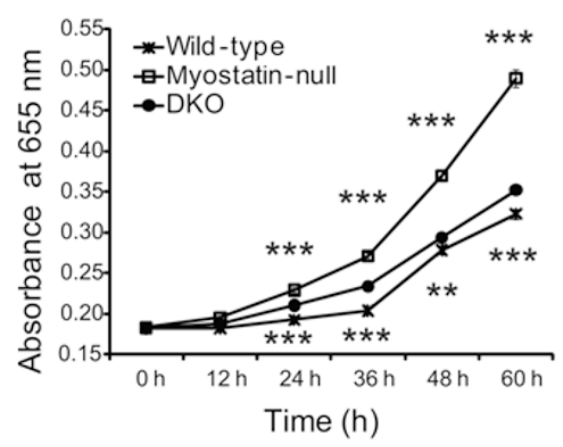

$\mathrm{H}$

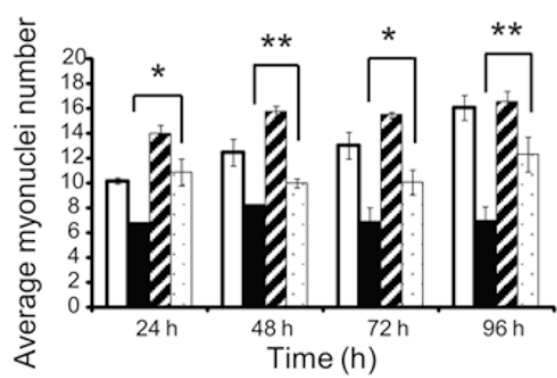

I

$J$
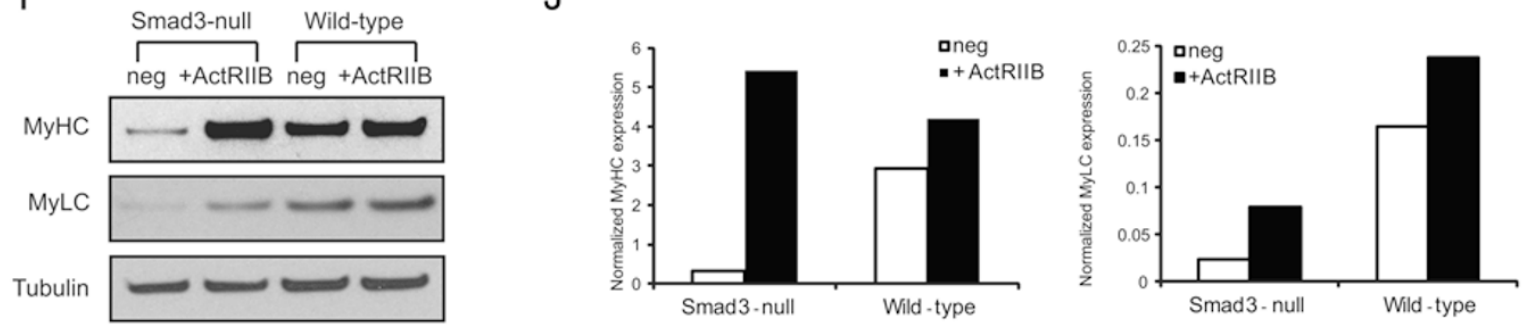

www.cell-research.com | Cell Research 
of myogenic differentiation also revealed an enhanced fusion index and an increase in average myonuclei number in the primary myotubes from DKO mice when compared to Smad3-null controls (Figure 5G, 5H and Supplementary information, Figure S6C). These data therefore suggest that myoblasts isolated from DKO mice demonstrate improved myogenesis when compared to myoblasts isolated from Smad3-null mice, which is consistent with the enhanced proliferation and differentiation observed in myostatin-null mice. Therefore, loss of myostatin appears to partially rescue the defective myoblast proliferation and differentiation phenotype observed in Smad3-null primary myoblast cultures.

Neutralization of myostatin results in increased MyHC protein levels in Smad3-null myotubes

Loss of myostatin partially rescues muscle atrophy in Smad3-null mice. In order to further confirm the postnatal role of myostatin in Smad3-null muscle atrophy, we neutralized endogenous myostatin by treating WT and Smad3-null primary culture with the soluble extracellular domain of activin type IIB receptor (ActRIIB), also known as soluble ActRIIB. After $48 \mathrm{~h}$ of treatment, MyHC and MyLC, important myogenic markers during differentiation, were measured by western blot. The results showed that neutralizing endogenous myostatin in primary culture significantly rescued $\mathrm{MyHC}$ protein levels in Smad3-null primary myotubes at $48 \mathrm{~h}$ post differentiation (Figure 5I and 5J). The expression level of another marker, MyLC, was also improved considerably (Figure 5I and 5J). This result further confirms the role of myostatin in muscle atrophy of Smad3-null mice.

\section{Discussion}

Among the TGF- $\beta$ superfamily members, TGF- $\beta$ and myostatin rely on canonical Smad signaling, specifically Smad2/3, to elicit biological functions during myogenesis $[11,12,26]$. Since myostatin is a negative regulator of myogenesis, one might expect that loss of Smad3 would enhance myogenesis due to interference with the myostatin-signaling pathway. However contrary to this, we show that lack of Smad3 results in dramatic muscular atrophy. Impaired SC function combined with increased proteasomal protein degradation appears to be the molecular mechanism behind the observed atrophy in Smad3null muscles.

\section{Smad3 signaling is required for proper function of SCs}

SCs are adult muscle precursor cells, and impaired function and/or number of SCs lead to reduced myogenesis and muscular atrophy [27]. In Smad3-null mice, there is a significant reduction in the SC number (Figure $2 \mathrm{E}$ and $2 \mathrm{~F}$ ), and data presented here suggest that this could be due to reduced self-renewal of SCs (Figure 2B and 2D). SC self-renewal refers to a process whereby a pool of myoblasts (derived from activated SCs), which express high levels of Pax7, withdraws from proliferation to replenish the SC population [28, 29]. Therefore, proliferation rate plays an important role in determining the pool of self-renewed SCs [8] during postnatal myogenesis. Cell cycle progression and proliferation of myoblasts are in turn regulated at $\mathrm{G}_{1} / \mathrm{S}$ and $\mathrm{G}_{2} / \mathrm{M}$ checkpoints, and perturbations at the checkpoints would lead to altered proliferation of myoblasts, which would in turn affect SC self-renewal. Our data here clearly demonstrate that in Smad3-inactivated myoblasts, there is increased cell cycle arrest in $G_{1}$ and $G_{2} / M$ phases of the cell cycle (Table 1). Furthermore, there is significant reduction in cyclin-E and Cdk2 expression, which in turn leads to hypophosphorylation of $\mathrm{Rb}$ (Figure 1D) and cell cycle arrest, resulting in the reduced proliferation rate observed in Smad3-null myoblasts (Figure 1B and 1C). This, we suspect, would lead to a diminished pool of myoblasts and reduced self-renewal of SCs.

\section{Lack of Smad3 severely affects myogenesis}

Differentiated Smad3-null myotubes showed an atrophic phenotype (Supplementary information, Figure S3), with both reduced fusion index and reduced average myonuclei number (Figure $1 \mathrm{~F}$ and $1 \mathrm{G}$ ). The fusion defects were further confirmed by reduced expression of three major fusion-related genes, caveolin $3, \beta_{1} D$ integrin and SHP-2 (Figure $1 \mathrm{H}$ and $1 \mathrm{~J}$ ). Caveolin 3 and $\beta_{1} \mathrm{D}$ integrin are membrane-associated proteins, which play important roles in myoblast fusion. SHP-2 is a known upstream modulator of the NFATc2 pathway, which is important for fusion between nascent myotubes and myoblasts [30]. Therefore, results presented here suggest that Smad3 is essential for proper temporal expression of differentiation genes.

\section{Muscle atrophy seen in Smad3-null muscles could be due to increased myostatin expression}

Both neonatal (data not shown) and 6-week-old postnatal Smad3-null mice show severe muscle fiber atrophy (Figure 1A). Skeletal muscle atrophy could be due to reduced protein synthesis and/or increased protein catabolism due to targeted ubiquitination of muscle-specific proteins. Two muscle-specific E3 ligases, Atrogin1 and MuRF1, are up-regulated in skeletal muscle tissue in response to numerous atrophic signals [31-33]. Western blot analysis confirmed that there is increased ubiquitination of intracellular proteins in skeletal muscle tis- 
sue from Smad3-null mice as compared to control mice (Figure 4A). Furthermore, real-time PCR and western blot analysis confirmed that MuRF1 was up-regulated in Smad3-null muscles (Figure 4A and 4B). Previous studies showed that expression of MuRF1 could be regulated by either the FoxO1 or FoxO3 transcription factor during skeletal muscle atrophy [34]. In this study, we did not detect any changes in the expression of FoxO1 at both total and phosphorylated protein level (Figure 4A). Therefore, we speculate that up-regulation of MuRF1 in Smad3null mice might be due to an increase in FoxO3 levels or activity. Alternatively, this could be due to an increase in the activity of NF- $\kappa B$ transcription factors, which can be activated by inflammatory cytokines [14, 35]. Consistent with increased MuRF1 levels, MyHC, a known target of MuRF1 [25], was down-regulated (Figure 4A and 4B). Thus, these results clearly suggest that the muscular atrophy seen in Smad3-null mice is much akin to cachecticlike muscle wasting. Although there was no significant change in terms of Akt phosphorylation, the impact of reduced protein synthesis cannot be ruled out at this stage, as increased levels of myostatin can also inhibit protein synthesis by down-regulating elongation factors (Lokireddy et al., unpublished data and see discussion below).

Our search for mechanism revealed increased expression of myostatin in Smad3-null mice (Figure 3A and 3C). Myostatin is a secreted growth factor, which has been previously shown to be a potent negative regulator of myogenesis. Loss of myostatin results in increased muscle growth due to increased SC number and activation [8]. Furthermore, myoblasts derived from myostatinnull SCs show increased proliferation and enhanced differentiation [12, 36]. In contrast, increased levels of myostatin have been shown to inhibit myoblast proliferation, arresting cells at the $G_{1}$ to $S$ transition, further resulting in reduced differentiation [7]. Furthermore, increased myostatin levels have also been shown to inhibit SC activation and self-renewal $[8,9]$, and also result in the development of severe cachectic-like muscle wasting, through activating components of the ubiquitinproteasome pathway [37]. The data presented in this manuscript, as well as previously published reports, strongly support the notion that the increased expression of myostatin observed in Smad3-null mice may be primarily responsible for the impaired SC function and increased protein catabolism.

Consistent with this hypothesis, myoblasts from DKO mice showed significantly increased proliferation when compared to Smad3-null primary myoblasts and moreover had a higher rate of proliferation than that of WT primary myoblasts (Figure 5F). Defects in fusion, during differentiation, were also partially recovered (Figure 5G,
$5 \mathrm{H}$ and Supplementary information, Figure S6C). Both fusion index and average myonuclei number increased in DKO myotubes as compared to Smad3-null myotubes. Furthermore, loss of myostatin, at least in part, rescued the skeletal muscle atrophy phenotype observed in Smad3-null mice, as demonstrated by the increased musculature observed in DKO mice when compared to Smad3-null mice (Supplementary information, Table S1). Thus, the improved muscle mass and enhanced myogenesis in DKO mice provide evidence to support the role of myostatin in the progression of the atrophic phenotype in Smad3-null mice.

Myostatin is widely known to signal through canonical Smad signaling (mainly Smad3) to inhibit myoblast proliferation, differentiation, SC activation and selfrenewal $[12,26,38]$. However, other signaling pathways including Smad2 are also shown to be involved in myostatin signaling $[9,13,39-42]$. In this study, higher myostatin level was shown to be, in part, responsible for the muscle atrophy in Smad3-null mice. This further suggests that myostatin could signal independently of Smad3 via either Smad2 or other signaling pathways, such as p38 mitogen-activated protein kinase (MAPK), c-Jun Nterminal kinase (JNK), and phosphatidylinositol 3-kinase (PI3K) pathways as shown previously [9, 39-42]. In the present manuscript, we have provided evidence to support the critical role of $\mathrm{Smad} 3$ in regulation of postnatal myogenesis and SC function in mice. Absence of Smad3 leads to impaired SC self-renewal, which is important for maintenance of the steady-state SC population during postnatal myogenesis. In addition, primary myoblasts derived from Smad3-null SCs exhibit defective proliferation and differentiation. Therefore, we propose that the dramatic atrophy observed in the absence of Smad3 may, in part, be due to impaired SC function. Smad3null muscle also undergoes enhanced protein degradation through up-regulation of MuRF1 and ubiquitinproteasome system. Furthermore, we also find increased myostatin expression and decreased IGF-1 expression in Smad3-null muscle and primary cultures. Since myostatin acts as a potent negative regulator in muscle growth, it is quite possible that elevated levels of myostatin may contribute to the muscle atrophy in Smad3-null mice. In addition, inactivation of myostatin in Smad3-null mice (DKO) partially rescues the loss of muscle mass, as well as improves the myogenic potential of SC-derived myoblasts in vitro. Nevertheless, inactivation of myostatin is unable to fully compensate for the muscle wasting observed in Smad3-null mice, suggesting the involvement of additional factors, as yet to be determined, which also contribute to the progression of the atrophic phenotype in Smad3-null mice. 


\section{Materials and Methods}

\section{Animal care}

Heterozygote Smad3-null mice were kindly gifted by Prof Walter Wahli (University of Lausanne, Lausanne, Switzerland), which were bred and genotyped according to the previously published protocol [14]. Heterozygote myostatin-null mice were a gift from Prof Se-Jin Lee (The Johns Hopkins University, USA) and were genotyped according to previously published reports [3, 15]. Mice were maintained on standard chow diet at a constant temperature $\left(20{ }^{\circ} \mathrm{C}\right)$ under a $12 \mathrm{~h} / 12 \mathrm{~h}$ artificial light/dark cycle with unlimited access to water. All experiments were performed according to the approved protocols of the institute animal ethics committee (IACUC), Singapore.

\section{Cell culture}

C2C12 myoblasts were cultured in proliferation medium, which consisted of Dulbecco's Modified Eagle Medium (DMEM; Invitrogen) supplemented with 10\% Fetal Bovine Serum (FBS; Invitrogen). For differentiation, $\mathrm{C} 2 \mathrm{C} 12$ cells were plated at a density of 25000 cells $/ \mathrm{cm}^{2}$. After an overnight attachment period, $\mathrm{C} 2 \mathrm{C} 12$ cells were induced to differentiate in low-serum media (DMEM with $2 \%$ Horse Serum (HS; Invitrogen)). Primary myoblasts were cultured from hind-limb muscles using a modified method of Partridge TA [16]. Briefly, hind-limb muscles were excised, minced and then digested in $0.2 \%$ collagenase type $1 \mathrm{~A}$ for $90 \mathrm{~min}$. Fibroblasts were removed by preplating the cells on uncoated plates for $3 \mathrm{~h}$. Adhered myoblasts were cultured on $10 \%$ Matrigel-coated plates (BD Biosciences) and were maintained in the proliferation medium, which consists of DMEM with $20 \% \mathrm{FBS}, 10 \% \mathrm{HS}$ and $1 \%$ chicken embryo extract (CEE) at $37{ }^{\circ} \mathrm{C} / 5 \% \mathrm{CO}_{2}$. Primary myoblast differentiation was induced as described above. For the neutralization of myostatin in primary culture, the isolated primary myoblasts were seeded at the density of $25000 \mathrm{cells} / \mathrm{cm}^{2}$ in growth media on $10 \%$ Matrigel-coated six-well plates. After overnight attachment, primary myoblasts were induced to differentiate with $(0 \mathrm{~h}+3 \mu \mathrm{g} / \mathrm{ml}$ soluble ActRIIB) or without soluble ActRIIB $(0 \mathrm{~h}$ $+0 \mu \mathrm{g} / \mathrm{ml}$ soluble ActRIIB) for $48 \mathrm{~h}$. For the treatment of proteasome inhibitor, primary myotubes $(48 \mathrm{~h})$ were incubated for $10 \mathrm{~h}$ with epoxomicin $(48 \mathrm{~h}+100 \mathrm{nM}$ epox; Sigma, USA) or without epoxomicin $(48 \mathrm{~h}+0 \mathrm{nM}$ epox $)$.

\section{Proliferation assay}

Myoblast proliferation was assessed as described previously [7]. Briefly, primary myoblasts or $\mathrm{C} 2 \mathrm{C} 12$ cells were seeded on 96-well plates at a density of 1000 cells per well in proliferation medium. Myoblasts were subsequently grown and fixed at regular $12 \mathrm{~h}$ intervals. Proliferation was assessed using the methylene blue photometric end-point assay as previously described [7].

\section{Determination of SC number on single muscle fibers}

Single muscle fibers from $M$. gastrocnemius muscle were isolated by the method of Rosenblatt et al. [17]. Isolated muscle fibers were placed in four-well Lab-Tek chamber slides (Nunc), fixed in $4 \%$ paraformaldehyde for $10 \mathrm{~min}$ and rinsed in PBS. The fibers were then permeabilized in $0.5 \%$ TritonX-100 in PBS and blocked with $10 \%$ normal goat serum (NGS) and $0.35 \%$ carrageenan- $\lambda(\mathrm{c} \lambda)$ in PBS for $1 \mathrm{~h}$. Fibers were incubated with mouse anti-Pax7 antibody (1:100; Developmental Studies Hybridoma Bank; DSHB) in
$5 \%$ NGS and $0.35 \% \mathrm{c} \lambda$ in PBS overnight, followed by incubation with the biotinylated sheep anti-mouse IgG (1:300; GE Healthcare Life Sciences) in 5\% NGS and $0.35 \%$ c $\lambda$ in PBS for $1 \mathrm{~h}$. After $3 \times$ TBS-T washes, fibers were incubated with the streptavidin-conjugated Alexa Fluor 488 (1:400; Molecular Probes) in 5\% NGS and $0.35 \%$ c $\lambda$ in PBS for $1 \mathrm{~h}$, counterstained with DAPI (1:1 000; Molecular Probes) and mounted with ProLong Gold antifade reagent (Invitrogen). Immunofluorescence images were captured using the Carl Zeiss LSM 510 META laser-scanning confocal microscope and LSM 510 META software, with a Zeiss Plan-NeoFluar $10 \times / 0.30 \times$ objective (Carl Zeiss MicroImaging, Inc.).

\section{Pax7/MyoD immunocytochemistry}

Primary myoblasts were fixed with $70 \%$ ethanol: formaldehyde:acetic acid (20:2:1) for $30 \mathrm{~s}$ and rinsed three times with PBS. Cells were permeabilized in $0.1 \%$ TritonX-100 in PBS and washed with PBS. Cells were blocked with 5\% NGS, 5\% normal sheep serum (NSS) and $0.35 \%$ carrageenan $-\lambda(\mathrm{c} \lambda)$ in PBS and incubated with mouse anti-Pax 7 antibody $(1: 100$; DSHB) and rabbit antiMyoD antibody (1:100; Santa Cruz Biotechnology) in 5\% NGS and $0.35 \% \mathrm{c} \lambda$ in PBS overnight at $4{ }^{\circ} \mathrm{C}$. After washing with TBS-T for three times, myoblasts were incubated for $1 \mathrm{~h}$ with biotinylated sheep anti-mouse IgG (1:300; GE Healthcare Life Sciences) in PBS containing 5\% NGS and $0.35 \% \mathrm{c} \lambda$ and then for $1 \mathrm{~h}$ in streptavidin-conjugated Alexa Fluor 488 (1:400) and Alexa Fluor 546 conjugated goat anti-rabbit IgG (IgG; 1:300; Molecular Probes) in $5 \%$ NGS, $5 \%$ NSS and $0.35 \% \mathrm{c} \lambda$ in PBS. After washing in TBS-T twice, myoblasts were stained with DAPI (1:1 000) and mounted with ProLong Gold antifade reagent. Immunofluorescence images were captured using the Carl Zeiss LSM 510 META laser-scanning confocal microscope and LSM 510 META software, with a Zeiss Plan-NeoFluar $10 \times$ and $20 \times$ objectives (Carl Zeiss MicroImaging, Inc.). For single muscle fibers, isolated muscle fibers were cultured in four-well Lab-Tek Permanox chamber slides (Nunc) coated with $10 \%$ Matrigel (BD Biosciences). After $144 \mathrm{~h}$ of culturing, primary myoblasts, which migrated from single muscle fibers, were fixed and immunostained with Pax7 and MyoD antibodies as described above.

\section{$H \&$ E staining}

$\mathrm{H} \& \mathrm{E}$ staining on cell cultures was performed according to McFarlane et al. [9]. Primary cultures were grown on Thermanox coverslips with $10 \%$ Matrigel coating. Myotubes were fixed at 24-h intervals and stained with Gill's hematoxylin, followed by $1 \%$ eosin (Merck). For H \& E staining on skeletal muscle sections, M. tibialis anterior (TA) muscles were covered with OCT compound and then frozen in isopentane cooled with liquid nitrogen. $10 \mu \mathrm{m}$ of transverse sections were cut and mounted on slides for $\mathrm{H}$ \& E staining. Images were captured using the Leica CTR $6500 \mathrm{mi}-$ croscope, equipped with the Leica DFC 310 FX camera and Image Pro Plus software (Media Cybernetics, USA).

\section{Western blot}

Protein extracts from myoblasts were made by lysing myoblasts in protein lysis buffer $(50 \mathrm{mM}$ Tris, $\mathrm{pH} 7.6,250 \mathrm{mM} \mathrm{NaCl}$, $5 \mathrm{mM}$ EDTA, $0.1 \%$ P-40, complete protease inhibitor cocktail from Roche Molecular Biochemicals). Skeletal muscle protein lysates were prepared by homogenizing muscles in RIPA buffer with EDTA, PMSF, aprotinin, $\mathrm{NaF}$ and $\mathrm{NaVO}_{4}$. Equal amount of proteins was resolved by SDS-PAGE (4-12\% gradient; Invitrogen) 
and transferred to a nitrocellulose membrane. The membranes were blocked in 5\% milk in TBS-T, and then incubated with primary and secondary antibodies in 5\% milk in TBS-T. Immunoreactivity was detected using Western Lightning ${ }^{\mathrm{TM}}$ Chemiluminescence Reagent Plus (PerkinElmer). Band density was analyzed using the Quantity One imaging software (Bio-Rad). For Rb phosphorylation analysis, proteins were separated by $6 \%$ SDS-PAGE. Details of the antibody sources and dilutions used in this manuscript are provided in Supplementary information, Table S2.

\section{$R N A$ preparation and quantitative real-time PCR analysis}

Total RNA was isolated using TRIzol reagent (Invitrogen), and RNA integrity was monitored by electrophoresis. cDNA was synthesized according to iScript cDNA Synthesis kit (Bio-Rad). Quantitative real-time PCR reactions were carried out in triplicate using SsoFast EvaGreen supermix (Bio-Rad) and the CFX96 RealTime System (Bio-Rad). Gene expression levels were normalized against that of GAPDH. Fold change of gene expression was calculated using the delta-delta $\mathrm{Ct}$ method. The sequences of primers used in this manuscript are provided in Supplementary information, Table S3.

\section{Establishment of stable shSmad3 and control C2C12 cell lines}

Two different sets of shRNA sequences were designed to specifically target the mouse Smad3 gene using the online software, RNAi finder and RNAi converter, available at the Applied Biosystems website (http://www.ambion.com/techlib/misc/siRNA_ finder.html and http://www.ambion.com/techlib/misc/psilencer converter.html): 5'-GATCCACTTTCTACTGCCACTTGGTTCAAGAGACCAAGTGGCAGTAGAAAGTTTA-3' (sense) and 5'-AGCTTAAACTTTCTACTGCCACTTGGTCTCTTGAACCAAGTGGCAGTAGAAAGTG-3' (anti-sense) for shSmad3-1 and 5'-GATCCGTTCTCCAGAGTTAAAAGCTTCAAGAGAGCTTTTAACTCTGGAGAACTTA-3' (sense) and 5'-AGCTTAAGTTCTCCAGAGTTAAAAGCTCTCTTGAAGCTTTTAACTCTGGAGAACG-3' (anti-sense) for shSmad3-2. The oligos were annealed and ligated into the pSilencer vector according to protocol recommended by the manufacturer (Applied Biosystems, USA). Sequence-verified constructs were selected and transfected into C2C12 myoblasts using Lipofectamine 2000 (Invitrogen). The stable cell lines were selected by continued puromycin treatment for a period of 20 days. A negative control pSilencer vector that expresses a hairpin siRNA with limited homology to any known sequences in the human, mouse and rat genomes databases was used. Negative control cells were maintained simultaneously, under the same conditions as described above.

\section{Flow cytometry}

Control and shSmad3 C2C12 myoblasts were cultured in proliferation medium and harvested. In all, 1-3 million cells were counted and centrifuged at $1000 \times g$ for $5 \mathrm{~min}$. After washing with cold PBS, cells were transferred to $10-\mathrm{ml}$ glass tubes and washed again. Supernatant was carefully aspirated and $1 \mathrm{ml}$ of ice-cold $70 \%$ ethanol was slowly added while vortexing at low speed. Fixed cells were stored at $-20{ }^{\circ} \mathrm{C}$ until staining. Cells were centrifuged at $1000 \times g$ for $5 \mathrm{~min}$ and $70 \%$ ethanol was carefully aspirated. While cells were vortexed at low speed, $1 \mathrm{ml}$ of staining mixture $(0.1 \mathrm{mg} / \mathrm{ml}$ propidium iodide and $0.05 \mathrm{mg} / \mathrm{ml} \mathrm{ribo-}$ nuclease) was added slowly. After 45 min of incubation at $4{ }^{\circ} \mathrm{C}$, cells were washed twice with cold PBS. Then, $1 \mathrm{ml}$ of cold PBS was added and cells were transferred to FACS tubes and examined for propidium iodide fluorescence using a flow cytometer (FACSCalibur, Becton-Dickinson) and analyzed using ModFit software (Becton-Dickinson).

\section{Purification of the recombinant extracellular domain of mouse ActRIIB}

The extracellular domain of mouse ActRIIB cDNA was amplified by PCR and cloned in the pET-16b protein expression system (Novagen) according to the manufacturer's protocol (Novagen). The construct was transformed into BL21 bacterial strain. The soluble ActRIIB protein was expressed and purified according to Sharma et al. [18]. The biological activity of the recombinant soluble ActRIIB was measured by myoblast proliferation assay.

\section{Statistical analysis}

Statistical significance was performed using the one-way ANOVA and the two-tailed Student's $t$-test, and results were considered significant at $P<0.05\left({ }^{*}\right), P<0.01\left({ }^{* *}\right)$ or $P<0.001\left(^{* * *}\right)$. Results were expressed as mean \pm SEM (standard error of mean).

\section{Acknowledgments}

We would like to thank Prof Se-Jin Lee (The Johns Hopkins University, USA) for the gift of the myostatin-null mice, and Esther Latres (Regeneron Pharmaceuticals, USA) for providing the Atrogin1 and MuRF1 antibodies used in this study. We would like to thank Developmental Studies Hybridoma Bank for some of the antibodies used in this study. We are indebted to Biomedical Research Council (BMRC), Singapore, for financial support.

\section{References}

1 Bischoff R. Analysis of muscle regeneration using single myofibers in culture. Med Sci Sports Exerc 1989; 21:S164-S172.

2 Grounds MD, Yablonka-Reuveni Z. Molecular and cell biology of skeletal muscle regeneration. Mol Cell Biol Hum Dis Ser 1993; 3:210-256.

3 McPherron AC, Lawler AM, Lee SJ. Regulation of skeletal muscle mass in mice by a new TGF-beta superfamily member. Nature 1997; 387:83-90.

4 Kambadur R, Sharma M, Smith TP, Bass JJ. Mutations in myostatin (GDF8) in double-muscled Belgian Blue and Piedmontese cattle. Genome Res 1997; 7:910-916.

5 Reisz-Porszasz S, Bhasin S, Artaza JN, et al. Lower skeletal muscle mass in male transgenic mice with muscle-specific overexpression of myostatin. Am J Physiol Endocrinol Metab 2003; 285:E876-E888.

6 Zimmers TA, Davies MV, Koniaris LG, et al. Induction of cachexia in mice by systemically administered myostatin. Science 2002; 296:1486-1488.

7 Thomas M, Langley B, Berry C, et al. Myostatin, a negative regulator of muscle growth, functions by inhibiting myoblast proliferation. J Biol Chem 2000; 275:40235-40243.

8 McCroskery S, Thomas M, Maxwell L, Sharma M, Kambadur R. Myostatin negatively regulates satellite cell activation 
and self-renewal. J Cell Biol 2003; 162:1135-1147.

9 McFarlane C, Hennebry A, Thomas M, et al. Myostatin signals through Pax7 to regulate satellite cell self-renewal. Exp Cell Res 2008; 314:317-329.

10 Liu D, Black BL, Derynck R. TGF-beta inhibits muscle differentiation through functional repression of myogenic transcription factors by Smad3. Genes Dev 2001; 15:2950-2966.

11 Liu D, Kang JS, Derynck R. TGF-beta-activated Smad3 represses MEF2-dependent transcription in myogenic differentiation. EMBO J 2004; 23:1557-1566.

12 Langley B, Thomas M, Bishop A, et al. Myostatin inhibits myoblast differentiation by down-regulating MyoD expression. J Biol Chem 2002; 277:49831-49840.

13 Li ZB, Kollias HD, Wagner KR. Myostatin directly regulates skeletal muscle fibrosis. J Biol Chem 2008; 283:19371-19378.

14 Yang X, Letterio JJ, Lechleider RJ, et al. Targeted disruption of SMAD3 results in impaired mucosal immunity and diminished T cell responsiveness to TGF-beta. EMBO J 1999; 18:1280-1291.

15 Li ZF, Shelton GD, Engvall E. Elimination of myostatin does not combat muscular dystrophy in dy mice but increases postnatal lethality. Am J Pathol 2005; 166:491-497.

16 Partridge TA. Tissue culture of skeletal muscle. Methods Mol Biol 1997; 75:131-144.

17 Rosenblatt JD, Lunt AI, Parry DJ, Partridge TA. Culturing satellite cells from living single muscle fiber explants. In Vitro Cell Dev Biol Anim 1995; 31:773-779.

18 Sharma M, Kambadur R, Matthews KG, et al. Myostatin, a transforming growth factor-beta superfamily member, is expressed in heart muscle and is upregulated in cardiomyocytes after infarct. J Cell Physiol 1999; 180:1-9.

19 Sherr CJ. G1 phase progression: cycling on cue. Cell 1994; 79:551-555.

20 Galbiati F, Volonte D, Engelman JA, Scherer PE, Lisanti MP. Targeted down-regulation of caveolin-3 is sufficient to inhibit myotube formation in differentiating $\mathrm{C} 2 \mathrm{C} 12$ myoblasts. Transient activation of p38 mitogen-activated protein kinase is required for induction of caveolin-3 expression and subsequent myotube formation. J Biol Chem 1999; 274:30315-30321.

21 Zhidkova NI, Belkin AM, Mayne R. Novel isoform of beta 1 integrin expressed in skeletal and cardiac muscle. Biochem Biophys Res Commun 1995; 214:279-285.

22 Schwander M, Leu M, Stumm M, et al. Beta1 integrins regulate myoblast fusion and sarcomere assembly. Dev Cell 2003; 4:673-685.

23 Kontaridis MI, Eminaga S, Fornaro M, et al. SHP-2 positively regulates myogenesis by coupling to the Rho GTPase signaling pathway. Mol Cell Biol 2004; 24:5340-5352.

24 de Oliveira MV, Marin TM, Clemente CF, et al. SHP-2 regulates myogenesis by coupling to FAK signaling pathway. FEBS Lett 2009; 583:2975-2981.

25 Clarke BA, Drujan D, Willis MS, et al. The E3 Ligase MuRF1 degrades myosin heavy chain protein in dexamethasone-treated skeletal muscle. Cell Metab 2007; 6:376-385.

26 Forbes D, Jackman M, Bishop A, et al. Myostatin auto-regulates its expression by feedback loop through Smad7 depen- dent mechanism. J Cell Physiol 2006; 206:264-272.

27 Thornell LE, Lindstom M, Renault V, et al. Satellite cell dysfunction contributes to the progressive muscle atrophy in myotonic dystrophy type 1. Neuropathol Appl Neurobiol 2009; 35:603-613.

28 Olguin HC, Olwin BB. Pax-7 up-regulation inhibits myogenesis and cell cycle progression in satellite cells: a potential mechanism for self-renewal. Dev Biol 2004; 275:375-388.

29 Zammit PS, Golding JP, Nagata Y, et al. Muscle satellite cells adopt divergent fates: a mechanism for self-renewal? J Cell Biol 2004; 166:347-357.

30 Jansen KM, Pavlath GK. Mannose receptor regulates myoblast motility and muscle growth. J Cell Biol 2006; 174:403-413.

31 Gomes MD, Lecker SH, Jagoe RT, Navon A, Goldberg AL. Atrogin-1, a muscle-specific F-box protein highly expressed during muscle atrophy. Proc Natl Acad Sci USA 2001; 98:14440-14445.

32 Bodine SC, Latres E, Baumhueter S, et al. Identification of ubiquitin ligases required for skeletal muscle atrophy. Science 2001; 294:1704-1708.

33 Lecker SH, Jagoe RT, Gilbert A, et al. Multiple types of skeletal muscle atrophy involve a common program of changes in gene expression. FASEB J 2004; 18:39-51.

34 Sandri M, Lin J, Handschin C, et al. PGC-1alpha protects skeletal muscle from atrophy by suppressing FoxO3 action and atrophy-specific gene transcription. Proc Natl Acad Sci USA 2006; 103:16260-16265.

35 Senf SM, Dodd SL, McClung JM, Judge AR. Hsp70 overexpression inhibits NF-kappaB and Foxo3a transcriptional activities and prevents skeletal muscle atrophy. FASEB J 2008; 22:3836-3845.

36 Langley B, Thomas M, McFarlane C, et al. Myostatin inhibits rhabdomyosarcoma cell proliferation through an $\mathrm{Rb}$-independent pathway. Oncogene 2004; 23:524-534.

37 McFarlane C, Plummer E, Thomas M, et al. Myostatin induces cachexia by activating the ubiquitin proteolytic system through an NF-kappaB-independent, FoxO1-dependent mechanism. J Cell Physiol 2006; 209:501-514.

38 Zhu X, Topouzis S, Liang LF, Stotish RL. Myostatin signaling through Smad2, Smad3 and Smad4 is regulated by the inhibitory Smad7 by a negative feedback mechanism. Cytokine 2004; 26:262-272.

39 Yang W, Zhang Y, Li Y, Wu Z, Zhu D. Myostatin induces cyclin D1 degradation to cause cell cycle arrest through a phosphatidylinositol 3-kinase/AKT/GSK-3 beta pathway and is antagonized by insulin-like growth factor 1. J Biol Chem 2007; 282:3799-3808.

40 Philip B, Lu Z, Gao Y. Regulation of GDF-8 signaling by the p38 MAPK. Cell Signal 2005; 17:365- 375.

41 Huang Z, Chen D, Zhang K, et al. Regulation of myostatin signaling by c-Jun N-terminal kinase in $\mathrm{C} 2 \mathrm{C} 12$ cells. Cell Signal 2007; 19:2286-2295.

42 Ji M, Zhang Q, Ye J, et al. Myostatin induces p300 degradation to silence cyclin D1 expression through the PI3K/PTEN/ Akt pathway. Cell Signal 2008; 20:1452-1458.

(Supplementary information is linked to the online version of the paper on the Cell Research website.) 